\title{
AMB Express
}

\section{Indentification and determination of toxin genes of Vibrio strains caused hemorrhagic disease on red drum (Sciaenops ocellatus) by PCR method \\ --Manuscript Draft--}

\begin{tabular}{|c|c|c|}
\hline Manuscript Number: & \multicolumn{2}{|l|}{ AMBE-D-20-00237 } \\
\hline Full Title: & \multicolumn{2}{|c|}{$\begin{array}{l}\text { Indentification and determination of toxin genes of Vibrio strains caused hemorrhagic } \\
\text { disease on red drum (Sciaenops ocellatus) by PCR method }\end{array}$} \\
\hline Article Type: & \multicolumn{2}{|l|}{ Original article } \\
\hline Funding Information: & $\begin{array}{l}\text { Universidad de Huelva } \\
\text { (CT-2018-DHH-07) }\end{array}$ & A/Professor Nguyen Quang Linh \\
\hline Abstract: & \multicolumn{2}{|c|}{ 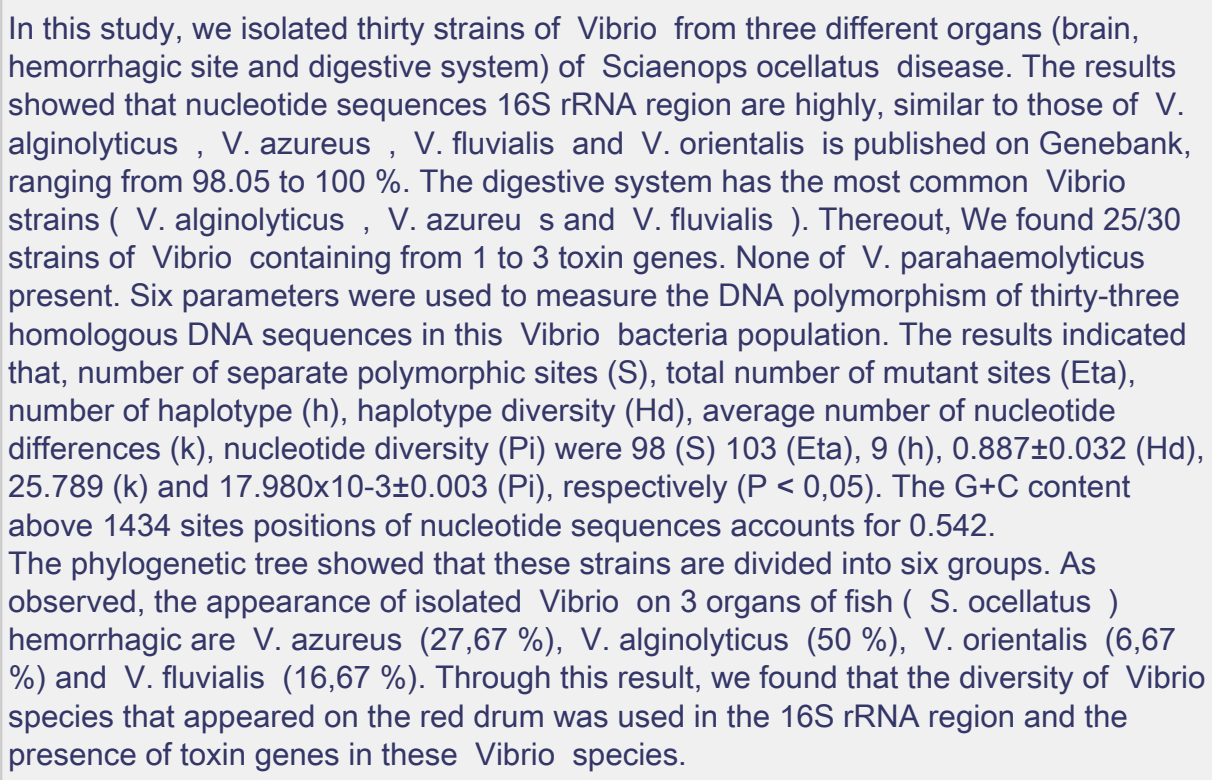 } \\
\hline Corresponding Author: & \multicolumn{2}{|c|}{$\begin{array}{l}\text { Nguyen Quang Linh, Dr. } \\
\text { Hue University } \\
\text { HUE, THUA THIEN HUE VIET NAM }\end{array}$} \\
\hline Corresponding Author E-Mail: & \multicolumn{2}{|c|}{ nguyenquanglinh@hueuni.edu.vn } \\
\hline \multicolumn{3}{|l|}{$\begin{array}{l}\text { Corresponding Author Secondary } \\
\text { Information: }\end{array}$} \\
\hline Corresponding Author's Institution: & \multicolumn{2}{|l|}{ Hue University } \\
\hline \multicolumn{3}{|l|}{$\begin{array}{l}\text { Corresponding Author's Secondary } \\
\text { Institution: }\end{array}$} \\
\hline First Author: & \multicolumn{2}{|l|}{ Nguyen Quang Linh, Dr. } \\
\hline \multicolumn{3}{|l|}{ First Author Secondary Information: } \\
\hline \multirow[t]{3}{*}{ Order of Authors: } & \multicolumn{2}{|l|}{ Nguyen Quang Linh, Dr. } \\
\hline & \multicolumn{2}{|l|}{ Pham Thi Hai Yen, ThS } \\
\hline & \multicolumn{2}{|c|}{ Nguyen Duy Quynh Tram, Dr. } \\
\hline \multicolumn{3}{|c|}{ Order of Authors Secondary Information: } \\
\hline \multirow[t]{2}{*}{ Suggested Reviewers: } & \multicolumn{2}{|c|}{$\begin{array}{l}\text { Tam Thi Pham, Dr. } \\
\text { Head, Hanoi University } \\
\text { tampt@hou.edu.vn } \\
\text { Related to aquatic Diseases and genetics }\end{array}$} \\
\hline & \multicolumn{2}{|c|}{$\begin{array}{l}\text { Hoa Phu Nguyen, Dr. } \\
\text { Hoad Hn Chi MAinh Citı/ I lnivorcitı of Torhnnlnav/ and Fdıınation }\end{array}$} \\
\hline
\end{tabular}




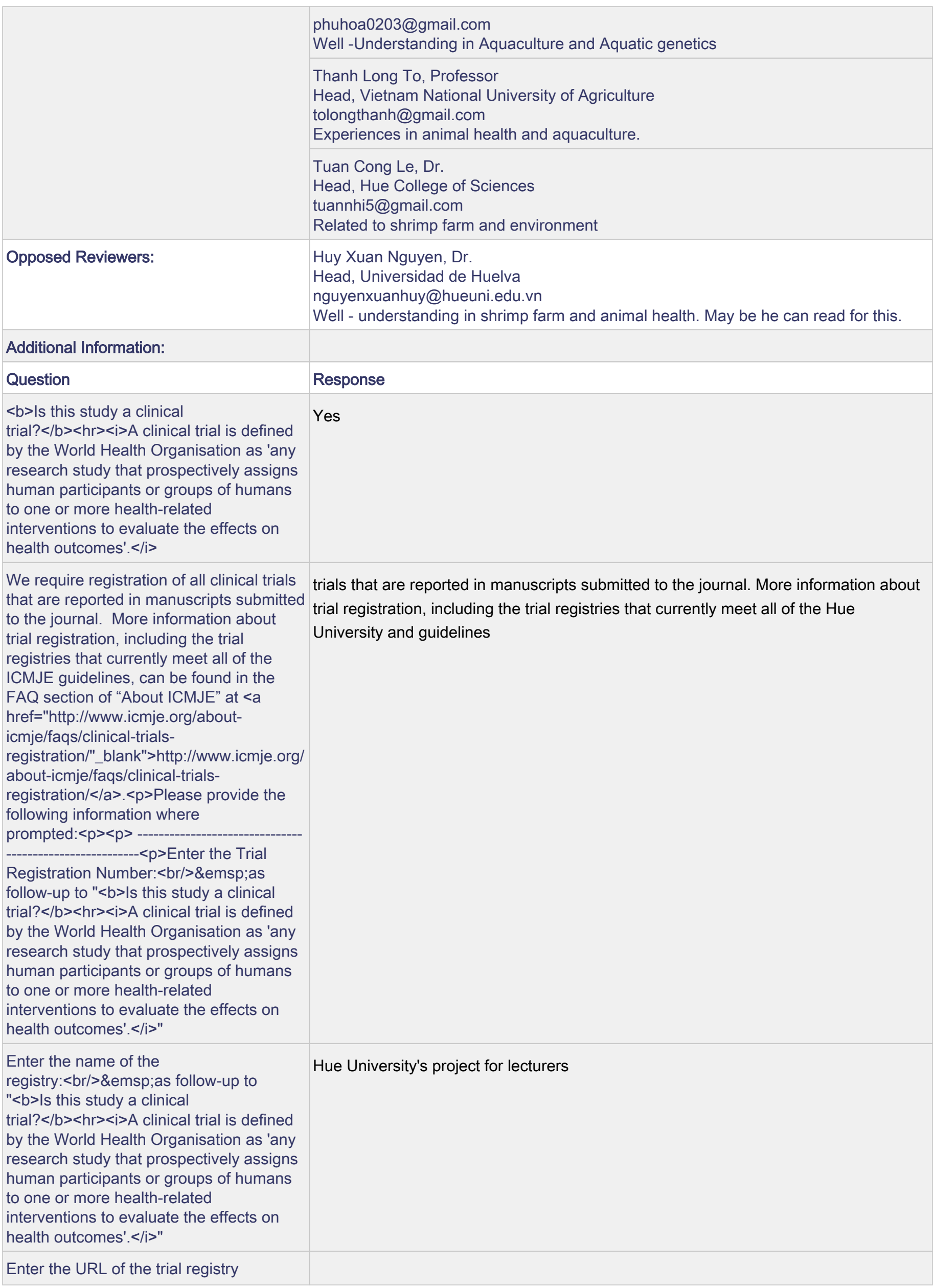


record: $<$ br/ $>$ \&emsp; as follow-up to " $<b>\mid s$ this study a clinical trial? $</ \mathrm{b}><\mathrm{hr}><\mathrm{i}>\mathrm{A}$ clinical trial is defined by the World Health Organisation as 'any research study that prospectively assigns human participants or groups of humans to one or more health-related interventions to evaluate the effects on health outcomes'.</i>"

Enter the date that you registered your trial (in $\mathrm{mm} / \mathrm{dd} / \mathrm{yyyy}$

format): $<$ br/ $>$ \&emsp; as follow-up to " $<$ b $>$ Is this study a clinical trial? $</ b><h r><i>A$ clinical trial is defined by the World Health Organisation as 'any research study that prospectively assigns human participants or groups of humans to one or more health-related interventions to evaluate the effects on health outcomes'.</i>"

Enter the date of enrolment of the first participant to the trial (in $\mathrm{mm} / \mathrm{dd} / \mathrm{yyyy}$ format): $<$ br/ $>$ \&emsp; as follow-up to " $<b>$ ls this study a clinical trial? $</ b><h r><i>A$ clinical trial is defined by the World Health Organisation as 'any research study that prospectively assigns human participants or groups of humans to one or more health-related interventions to evaluate the effects on health outcomes'.</i>"

Was your trial registered before the first participant was enrolled? (i.e.

prospectively registered) $<b r />\&$ emsp;as follow-up to " $<b>$ Is this study a clinical trial? $</ \mathrm{b}\rangle<\mathrm{hr}><\mathrm{i}>\mathrm{A}$ clinical trial is defined by the World Health Organisation as 'any research study that prospectively assigns human participants or groups of humans to one or more health-related interventions to evaluate the effects on health outcomes'.</i>"

Within your manuscript, have you also

I confirm I have provided trial registration details at the end of the abstract www.hueuni.edu.vn and all are allowing in $\mathrm{PhD}$ programme for students, who is

02-25-2019 following -up training programme.
Yes included details of your trial registration at the end of your abstract?

- Name of the registry

- Trial registration number

- Date of registration

- URL of trial registry record

Example: Trial registration: ISRCTN, ISRCTN12345678. Registered 28

September 2014, http://www.isrctn.com/ISRCTN12345678 as follow-up to "Was your trial registered before the first participant was enrolled? (i.e. prospectively registered)" 


\title{
Indentification and determination of toxin genes of Vibrio strains caused hemorrhagic disease on red drum (Sciaenops ocellatus) by pcr method
}

\author{
Nguyen Quang Linh ${ }^{1,2 *}$, Pham Thi Hai Yen ${ }^{1}$, Nguyen Duy Quynh Tram ${ }^{1}$ \\ Corresponding author: Nguyen Quang Linh; Email: nguyenquanglinh@hueuni.edu.vn
}

\begin{abstract}
In this study, we isolated thirty strains of Vibrio from three different organs (brain, hemorrhagic site and digestive system) of Sciaenops ocellatus disease. The results showed that nucleotide sequences 16S rRNA region are highly, similar to those of V. alginolyticus, V. azureus, $V$. fluvialis and V. orientalis is published on Genebank, ranging from 98.05 to $100 \%$. The digestive system has the most common Vibrio strains ( $V$. alginolyticus, V. azureus and V. fluvialis). Thereout, We found 25/30 strains of Vibrio containing from 1 to 3 toxin genes. None of $V$. parahaemolyticus present. Six parameters were used to measure the DNA polymorphism of thirty-three homologous DNA sequences in this Vibrio bacteria population. The results indicated that, number of separate polymorphic sites (S), total number of mutant sites (Eta), number of haplotype (h), haplotype diversity (Hd), average number of nucleotide differences $(\mathrm{k})$, nucleotide diversity $(\mathrm{Pi})$ were $98(\mathrm{~S}) 103(\mathrm{Eta}), 9(\mathrm{~h}), 0.887 \pm 0.032(\mathrm{Hd}), 25.789(\mathrm{k})$ and 17.980x10-3 $\pm 0.003(\mathrm{Pi})$, respectively $(\mathrm{P}<$ $0,05)$. The $\mathrm{G}+\mathrm{C}$ content above 1434 sites positions of nucleotide sequences accounts for 0.542 .

The phylogenetic tree showed that these strains are divided into six groups. As observed, the appearance of isolated Vibrio on 3 organs of fish (S. ocellatus) hemorrhagic are V. azureus (27,67\%), V. alginolyticus (50 $\%), V$. orientalis $(6,67 \%)$ and $V$. fluvialis $(16,67 \%)$. Through this result, we found that the diversity of Vibrio species that appeared on the red drum was used in the 16S rRNA region and the presence of toxin genes in these Vibrio species.
\end{abstract}

Keywords: Sciaenops ocellatus, TDH, TRH, TLH, ToxR, Toxin gene, Vibrio.

\section{Introduction}

More than 100 Vibrio spp. have been reported and are predominantly associated with a variety of marine, estuarine, or other aquatic habitats (Janda, Newton, \& Bopp, 2015). Red drum (Sciaenops ocellatus) was discovered originally in the Atlantic Ocean and the Gulf of Mexico; it was introduced into China in 1991 and since then it has been cultured extensively in several provinces in China (Zhang \& Sun, 2011). In recent years, red drum (S. ocellatus) mortalities associated with Streptococcus iniae infection (Eldar, A., et al., 1999), (Mmanda et al., 2014). There were seven Vibrio strains (includings $V$. vulnificus HM-TA-D2-L2-V2; V. vulnificus HM-TA-G2-V1-D2; V. brasiliensis HM-X-13/6; V. cholerae V-13/6; V. parahaemolyticus HM-17/6; V. cholerae HM-V-13/6 and V. vulnificus HM-X-13/6) deterted to cause hemorrhagic disease in red drum (S. ocellatus) had only th gene and none of Vibrio strains had tdh and trh genes (Hoang Tan Quang et al., 2020). The research identified this fish (S. ocellatus) viperin gene (SoVip) and analyzed its expression in relation to bacterial challenge. The complete gene of SoVip is $2570 \mathrm{bp}$ in length and contains six exons and five introns. The open reading frame of SoVip is $1065 \mathrm{bp}$, which is flanked by a 50 untranslated region (UTR) of $34 \mathrm{bp}$ and a 30 UTR of $350 \mathrm{bp}$ and the fish pathogen Edwardsiella tarda but down regulated by the fish pathogens Listonella anguillarum and Streptococcus iniae (Dang, Zhang, Hu, \& Sun, 2010). In this study, we described the identification and determination of toxin gene neutrality which was tested basing on three methods (Tajima, 1989), (Fu \& Li, 1993) and (Fu, 1995) showing that there has been an excess of low frequency polymorphisms relating to expectation, evidence for a deficiency of alleles, as would be expected from a recent population bottleneck and the evolution of the studied 30 strains bacteria Vibrio population was balancing selection, 
sudden contraction or in other words, rare alleles appeared in populations with low frequency. The studied population had very few individuals showing large differences in comparison with other individuals in the population.

\section{Materials and methods}

\section{Collection of fish disease}

In this study, we used thirty strains of bacteria with different morphologies isolated from three different organs in the fish (S. ocellatus) that have hemorrhagic disease (Fig 1) in Thua Thien Hue province, Vietnam, basing on the medium TCBS (Thiosulphate Citrate Bile Salt Sucrose).
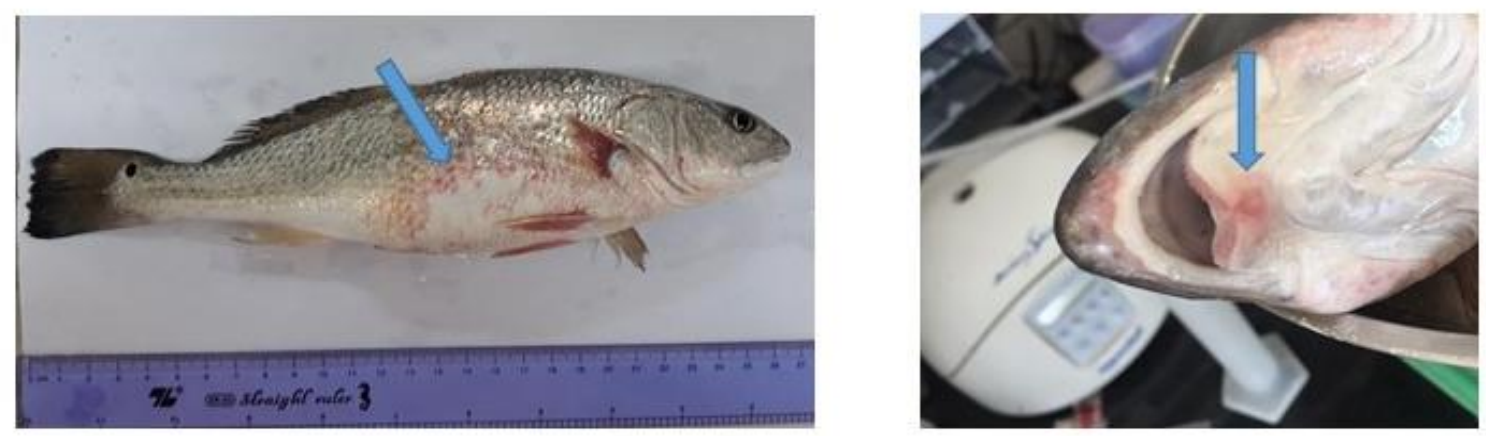

Fig. 1 Sample of Sciaenops ocellatus hemorrhagic signal

\section{Total DNA extraction method}

The DNA extraction method presented in this paper is an improved method of the standard phenol/chloroform method (Neumann, Pospiech, \& Schairer, 1992). We eliminated the lysis step that uses SDS/lysozyme or proteinase $\mathrm{K}$, and lysed cells directly by phenol. To extract the DNA from bacteria isolated from hemorrhagic disease in fish, 1 $\mathrm{mL}$ cell suspension was centrifuged at $8000 \mathrm{rpm}$ for 2 minutes, for the collection of pellet cells. After removing the supernatant, the cells were washed with $400 \mu \mathrm{l}$ STE Buffer (100 mM NaCl, $10 \mathrm{mM}$ Tris/ HCl, $1 \mathrm{mM}$ EDTA, pH 8.0) twice, then centrifuged at $8000 \mathrm{rpm}$ for $2 \mathrm{~min}$. The pellets were resuspended in $200 \mu \mathrm{TE}$ buffer $(10 \mathrm{mM} \mathrm{Tris} / \mathrm{HCl}, 1$ mM EDTA, $\mathrm{pH}$ 8.0). After this, $100 \mu \mathrm{l}$ Tris-saturated phenol ( $\mathrm{pH} 8.0$ ) was added to these tubes, followed by a vortexmixing step of $60 \mathrm{~s}$. The samples were subsequently centrifuged at $13000 \mathrm{rpm}$ for $5 \mathrm{~min}$ at $4^{\circ} \mathrm{C}$ to separate the aqueous phase from the organic phase. $160 \mu \mathrm{l}$ upper aqueous phase was transferred to a clean $1.5 \mathrm{ml}$ tube. $40 \mu \mathrm{TE}$ buffer was added to make $200 \mu \mathrm{l}$ and mixed with $100 \mu \mathrm{l}$ chloroform and centrifuged for $5 \mathrm{~min}$ at $13000 \mathrm{rpm}$ at $4^{\circ} \mathrm{C}$. Lysate was purified by chloroform extraction until a white interface was no longer present; this procedure might have to be repeated two to three times. $160 \mu 1$ upper aqueous phase was transferred to a clean $1.5 \mathrm{ml}$ tube. $40 \mu \mathrm{l}$ TE and 5 $\mu 1 \mathrm{RNase}\left(\right.$ at $10 \mathrm{mg} / \mathrm{ml}$ ) were added and incubated at $37^{\circ} \mathrm{C}$ for $10 \mathrm{~min}$ to digest RNA. Then $100 \mu \mathrm{l}$ chloroform was added to the tube, mixed well and centrifuged for $5 \mathrm{~min}$ at $13000 \mathrm{rpm}$ at $4{ }^{\circ} \mathrm{C} .150 \mu \mathrm{l}$ upper aqueous phase was transferred to a clean $1.5 \mathrm{ml}$ tube. The aqueous phase contained purified DNA and was directly used for the subsequent experiments or stored at $20^{\circ} \mathrm{C}$. The purity and yield of the DNA were assessed spectrophotometrically by calculating the $\mathrm{A}_{260} / \mathrm{A}_{280}$ ratios and the $\mathrm{A}_{260}$ values to determine protein impurities and DNA concentrations (Neumann et al., 1992).

\section{Determination of toxin gene}

The presence of toxin genes in Vibrio spp. strains were determined through the presence of genes encoding toxic proteins ( $t$ th, $t d h$, trh and tox $R$ ) which is based on specific primers for these genes (Table 1). PCR procedure: $50 \mathrm{ng}$ of total DNA, 10 pmol of each primer, $25 \mu 1$ PCR master mix $2 \times(2.4 \mathrm{mM}$ dNTP each, 0.3 units Taq DNA polymerase, Promega, USA), and sterile distilled water (total volume of $50 \mu \mathrm{L}$ ). PCR amplification was performed in MJ Minit ${ }^{\mathrm{TM}}$ Thermal Cycler (Bio-Rad, USA) as follows: $94{ }^{\circ} \mathrm{C}$ for 3 minutes; followed by 30 cycles at $94^{\circ} \mathrm{C}$ for 1 minute, $50^{\circ} \mathrm{C}$ for 1 minute, and $72^{\circ} \mathrm{C}$ for 1 minute; the last cycle of $72^{\circ} \mathrm{C}$ for 7 minutes. PCR products were used for electrophoresis 
on $1 \%$ agarose gel, using standard electrophoresis procedures in TAE $1 \mathrm{X}$ buffer with Ethydium bromide dye and read electrophoresis images by direct UV reading system (UV-transillumnator, Model: DyNa Light).

Table 1 Sequence of primers

\begin{tabular}{|c|c|c|c|c|}
\hline Genes & Primer names & Nucleotide sequences $5^{\prime} \rightarrow 3^{\prime}$ & Size (bp) & References \\
\hline \multirow{2}{*}{$\operatorname{tox} R$} & toxR-F & GTCTTCTGACGCAATCGTTG & \multirow{2}{*}{367} & Luan et al., 2007; \\
\hline & tox $R-\mathrm{R}$ & ATACGAGTGGTTGCTGTCATG & & Marlina et al., 2007 \\
\hline \multirow{2}{*}{$t d h$} & $t d h-\mathrm{F}$ & GTAAAGGTCTCTGACTTTTGGAC & \multirow{2}{*}{500} & Luan et al., 2007; \\
\hline & $t d h-\mathrm{R}$ & TGGAATAGAACCTTCATCTTCACC & & Marlina et al., 2007 \\
\hline \multirow{2}{*}{ trh } & $t r h-\mathrm{F}$ & TTGGCTTCGATATTTTCAGTATCT & \multirow{2}{*}{269} & Luan et al., 2007; \\
\hline & trh-R & CATAACAAACATATGCCCATTTCC & & Marlina et al., 2007 \\
\hline \multirow{2}{*}{ tlh } & $t l h-\mathrm{F}$ & AAAGCGGATTATGCAGAAGCACTG & \multirow{2}{*}{450} & Luan et al., 2007; \\
\hline & tlh-R & GCTACTTTCTAGCATTTTCTCTGC & & Marlina et al., 2007 \\
\hline
\end{tabular}

$t d h=$ Thermostable direct hemolysin, $t r h=$ TDH-related hemolysin, $t h=$ Thermolabile hemolysin, tox $R=$ Toxin operon (Luan et al., 2007), (Marlina et al., 2007).

\section{S rRNA Gene Amplification and Sequencing}

Performing PCR reaction to amplify the $16 \mathrm{~S}$ rRNA region, originating from genome with a pair of $16 \mathrm{~S}$ primers: 27F: AGAGTTTGATCMTGGCTCAG and 1492R: TACGGYTACCTTGTTACGACTT (Jeremy A Frank et al., 2008). The PCR reaction is performed on the Applied Biosystems - Life Technologies - Thermo Fisher Scientific - USA with a reaction component of $25 \mu$ PCR master mix $2 \times(2.4 \mathrm{mM}$ dNTP each, 0.3 units Taq DNA polymerase), 10 pmol of 27F primer, 10 pmol of 1492 primer, $1 \mu 1$ of total DNA $(50 \mathrm{ng} / \mu \mathrm{l})$ and sterile distilled water to a final volume of $50 \mu \mathrm{l}$. The $16 \mathrm{~S}$ rRNA gene region is amplified with the following thermal cycle: $95^{\circ} \mathrm{C} / 5$ minutes; 30 cycles $\mathrm{x}$ $\left(95^{\circ} \mathrm{C} / 60\right.$ seconds; $57^{\circ} \mathrm{C} / 50$ seconds; $72^{\circ} \mathrm{C} / 60$ seconds); $72^{\circ} \mathrm{C} / 10$ minutes. Aliquots $(10 \mu \mathrm{l})$ of PCR products were electrophoresed and visualized in $1 \%$ agarose gels using standard electrophoresis procedures in TAE $1 \mathrm{X}$ buffer with Ethydium bromide dye and read electrophoresis images by direct UV reading system (UV-transillumnator, Model: DyNa Light). Partial 16S rRNA genes of selected isolates in each site were sequenced by MACROGEN, Republic of Korea (dna.macrogen.com). Finally, 16S rRNA sequence of the isolation was compared with that of other microorganisms using BLAST (http://www.ncbi.nlm.nih.gov/BLAST/Blast.cgi).

\section{Sequencing and analyzing genetic relationships}

The PCR products of the 16S rRNA region are purified with Isolate II PCR and Gel (Bioline) kits. Then, they are sequenced directly by the dideoxy termination method on the ABI PRISM ${ }^{\circledR} 3100$ Avant Genetic Analyzer (Applied Biosystems) at Maccrogen Company, Korea (dna.macrogen.com).

The nucleotide sequences are arranged based on the Clustals program (Thompson, Gibson, Plewniak, Jeanmougin, \& Higgins, 1997) and edited by using BioEdit 7.0.5 software (Hall, 1999). Finally, 16S rRNA sequence of the isolation was compared with that of other microorganisms using BLAST (http://www.ncbi.nlm.nih.gov/BLAST/Blast.cgi).

The DNA polymorphism analysis is based on eight parameters including number of separate polymorphic sites (S), total number of mutant sites (Eta), number of haplotypes (h), haplotype diversity (Hd), average number of nucleotide differences $(\mathrm{k})$, nucleotide diversity $(\mathrm{Pi})$ are considered as a polymorphic measurement in the population (J. Rozas \& R. Rozas, 2005). Neutrality is tested based on three methods, Tajima's D test (Tajima, 1989), (Fu Y.X., \& Li, U.H.,1993) and (Fu, Y. X., 1995) using DNASP 6.0 software.

Phylogenetic tree showing genetic relationship will be built by MEGA X software (The Molecular Evolution Genetics Analysis), based on methods of UPGMA method (Sneath \& Sokal, 1973). The optimal tree with the sum of branch length equal to 0.08795656 is shown. The percentage of replicate trees in which the associated taxa clustered together in the bootstrap test (1000 replicates) are shown next to the branches (Felsenstein, J., 1985). The tree is drawn to scale, with branch lengths in the same units as those of the evolutionary distances used to infer the phylogenetic tree. The evolutionary distances were computed using the Maximum Composite Likelihood method (Koichiro Tamura, Masatoshi Nei, \& Kumar, 2004) and are in the units of the number of base substitutions per site. This analysis involved 48 nucleotide sequences. All ambiguous positions were removed for each sequence pair 
(pairwise deletion option). There were a total of 1434 positions in the final dataset. Evolutionary analyses were conducted in MEGA X (Kumar S., Stecher G., Li M., Knyaz C., \& K., 2018).

\section{Results}

\section{PCR result}

The results indicated that all PCR products of the 16S rRNA region in the studied of 30 isolated strain bacteria based on medium TCBS showed a single band with $100 \%$ amplification rate. All samples gave high DNA concentration and are clearly seen. The obtained size was approximately $1500 \mathrm{bp}$, which goes in line with the initial expected size (Fig. 2).

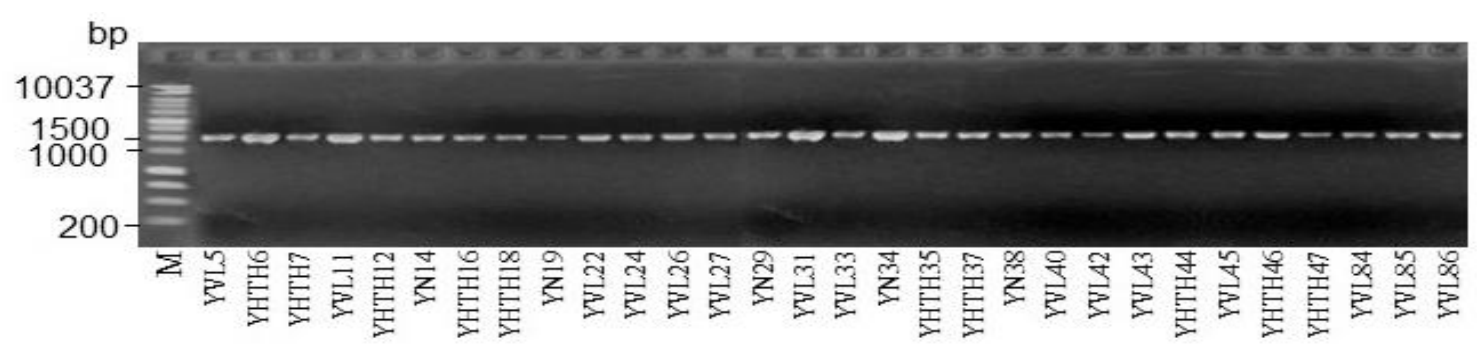

Fig. 2 Electrophoresis of PCR product. M: DNA mass scale (HyperLadder ${ }^{\mathrm{TM}} 1 \mathrm{~kb}$ (200 bp to $10037 \mathrm{bp}$ ), Bioline, Meridian Bioscience

The PCR products of the 16S rRNA region are purified with Isolate II PCR and Gel (Bioline) kits. Then, they are sequenced directly by the dideoxy terminator method on the ABI PRISM ${ }^{\circledR} 3100$ Avant Genetic Analyzer (Applied Biosystems) at Maccrogen Company, Korea (dna.macrogen.com). The results of the 16S rRNA region were about $1450 \mathrm{bp}$ for the remaining 30 isolated strain bacteria based on medium TCBS. The BLAST result on NCBI was used to verify and compare with the sequences of the Vibrio spp. with accession number Genebank (Table 2) showed that the nucleotide sequences obtained were highly similar to those of the V. alginolyticus, V. azureus, V. fluvialis and $V$. orientalis, ranging from 98,05 to $100 \%$ (Table 2).

\section{Determination of toxin gene}

The agarose gel electrophoresis of PCR products determined the presence of $t r h, t d h$, th and toxR genes at bands 269 bp, $500 \mathrm{bp}, 450 \mathrm{bp}$ and $367 \mathrm{bp}$, respectively (Fig. 2). We found 25/30 strains of Vibrio containing at least 1 toxic gene whereas 5 isolates carried out 3 toxin genes. However, none of these isolates consisted of all virulence toxins genes (Table 2). The results clearly indicate the presence of virulence toxins (trh, $t d h$ and $t h$ ) and a regulator toxin (toxR). A mong them, 18 isolates presented $t h$ while only 2 isolates were found to be carried out $t d h$ gene.

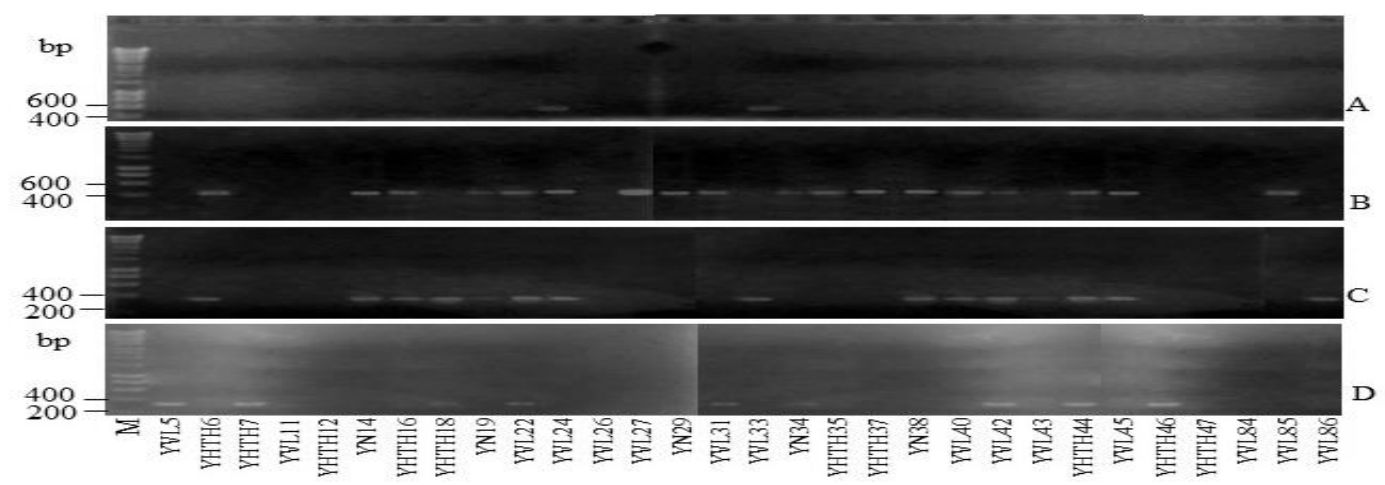

Fig. 3 Electrophoresis determination of toxin gene. M: DNA mass scale (HyperLadder ${ }^{\mathrm{TM}} 1 \mathrm{~kb}$ (200 bp to $10037 \mathrm{bp}$ ), Bioline, Meridian Bioscience). Fig A: PCR producr of gene $t d h$. Fig B: PCR producr of gene thl. Fig C: PCR producr of gene toxR and hình D: PCR nroducr of gene trh. 
Sequencing and analyzing genetic relationships

Table 2 Phylogenetic affiliation of isolates on the basis of 16S rRNA genes sequences by using BLAST programme in the GenBank database based on sequence similarity and Determination of toxin genes

\begin{tabular}{|c|c|c|c|c|c|c|c|c|}
\hline \multirow[t]{2}{*}{ No } & \multirow{2}{*}{$\begin{array}{c}\text { Sample } \\
\text { codes }\end{array}$} & \multirow[t]{2}{*}{ Closest species relative } & \multirow{2}{*}{$\begin{array}{c}\text { GenBank accession } \\
\text { number }\end{array}$} & \multirow{2}{*}{$\begin{array}{c}\text { Similarity } \\
(\%)\end{array}$} & \multicolumn{4}{|c|}{ Genes } \\
\hline & & & & & toxR & tdh & trh & tlh \\
\hline 1 & YN14 & Vibrio alginolyticus strain Va-F10 & MH298564.1 & 98,05 & + & - & - & + \\
\hline 2 & YN19 & Vibrio alginolyticus strain Va-F10 & MH298564.1 & 98,05 & + & - & - & + \\
\hline 3 & YN34 & Vibrio alginolyticus strain 4-14 & MN938360.1 & 99,65 & - & - & + & + \\
\hline 4 & YN38 & Vibrio alginolyticus strain Va-F10 & MH298564.1 & 98,05 & + & - & - & + \\
\hline 5 & YN43 & Vibrio alginolyticus strain 4-14 & MN938360.1 & 99,65 & + & - & - & - \\
\hline 6 & YHTH6 & Vibrio azureus strain Xmb005 & KT986135.1 & 100 & + & - & - & + \\
\hline 7 & YHTH7 & Vibrio alginolyticus strain 1-37 & MN874162.1 & 98,06 & - & - & + & - \\
\hline 8 & YHTH12 & Vibrio azureus strain Xmb005 & KT986135.1 & 100 & - & - & - & - \\
\hline 9 & YHTH16 & Vibrio fluvialis strain $2013 \mathrm{~V}-1044$ & СР051126.1 & 100 & + & - & - & + \\
\hline 10 & YHTH18 & Vibrio fluvialis strain $2013 \mathrm{~V}-1044$ & СР051126.1 & 100 & + & - & + & - \\
\hline 11 & YHTH35 & Vibrio azureus strain Xmb005 & KT986135.1 & 100 & - & - & - & + \\
\hline 12 & YHTH37 & Vibrio fluvialis strain $2013 \mathrm{~V}-1044$ & CP051126.1 & 100 & - & - & - & + \\
\hline 13 & YHTH44 & Vibrio alginolyticus strain 1-37 & MN874162.1 & 98,06 & + & - & + & + \\
\hline 14 & YHTH46 & Vibrio azureus strain Xmb005 & KT986135.1 & 100 & - & - & + & - \\
\hline 15 & YHTH47 & Vibrio fluvialis strain $2013 \mathrm{~V}-1044$ & СР051126.1 & 100 & - & - & - & - \\
\hline 16 & YVL5 & Vibrio azureus strain Xmb005 & KT986135.1 & 100 & - & - & + & - \\
\hline 17 & YVL11 & Vibrio azureus strain Xmb005 & KT986135.1 & 100 & - & - & - & - \\
\hline 18 & YVL22 & Vibrio alginolyticus strain 3-31 & MN843961.1 & 99,72 & + & - & + & + \\
\hline 19 & YVL24 & Vibrio alginolyticus strain 3-5 & MN938185.1 & 99,86 & + & + & - & + \\
\hline 20 & YVL26 & Vibrio alginolyticus strain $2015 \mathrm{AW}-0011$ & CP051109.1 & 99,59 & - & - & - & - \\
\hline 21 & YVL27 & Vibrio orientalis strain $5-13$ & MN945276.1 & 100 & - & - & - & + \\
\hline 22 & YVL29 & Vibrio alginolyticus strain 3-31 & MN843961.1 & 99,72 & - & - & - & + \\
\hline 23 & YVL31 & Vibrio alginolyticus strain 3-5 & MN938185.1 & 99,86 & - & - & + & + \\
\hline 24 & YVL33 & Vibrio azureus strain Xmb005 & KT986135.1 & 100 & + & + & - & - \\
\hline 25 & YVL40 & Vibrio alginolyticus strain $2015 A W-0011$ & СР051109.1 & 99,59 & + & - & - & + \\
\hline 26 & YVL42 & Vibrio orientalis strain $5-13$ & MN945276.1 & 100 & + & - & + & + \\
\hline 27 & YVL45 & Vibrio azureus strain Xmb005 & KT986135.1 & 100 & + & - & - & + \\
\hline 28 & YVL84 & Vibrio alginolyticus strain 3-31 & MN843961.1 & 99,72 & - & - & - & - \\
\hline 29 & YVL85 & Vibrio alginolyticus strain 3-5 & MN938185.1 & 99,86 & - & - & - & + \\
\hline 30 & YVL86 & Vibrio alginolyticus strain $2015 \mathrm{AW}-0011$ & CP051109.1 & 99,59 & + & - & - & - \\
\hline
\end{tabular}


Table 3 DNA diversity based on 16S rRNA region of strain bacteria Vibrio population using the programme DNASp 5.0 (J. Rozas \& R. Rozas, 2005)

\begin{tabular}{cccccccc}
$\begin{array}{c}\text { Genetic } \\
\text { region }\end{array}$ & S & Eta & H & $\begin{array}{c}\text { G+C content } \\
(1434 \text { sites })\end{array}$ & Hd & k & $\begin{array}{c}\text { Pi } \\
\left.(\mathbf{x 1 0})^{-3}\right)\end{array}$ \\
\hline $16 S$ rRNA & 98 & 103 & 9 & 0.542 & $0.887 \pm 0.032$ & 25.789 & $17.980 \pm 0.003$ \\
\hline
\end{tabular}

Number of variable sites (S); Total number of mutations (Eta); Number of Haplotypes (H); Haplotype (gene) diversity (Hd); Nucleotide diversity (per site) (Pi); Average number of nucleotide differences $(k)$

Six parameters including number of polymorphic sites $(\mathrm{S})$, total number of mutant sites (Eta), number of haplotypes $(\mathrm{h})$, haplotype diversity $(\mathrm{Hd})$, average number of nucleotide differences $(\mathrm{k})$, nucleotide diversity $(\mathrm{Pi})$ were used to evaluate the diversity of 30 studied Vibrio strains. As shown in table 4, ninety eight separate polymorphic positions (S) created 103 mutant positions (Eta) shown in 30 studied strain bacteria Vibrio were classified into nine types of haplotype (h) with haplotype diversity coefficient accounting for $0.887 \pm 0.032$ (Hd), the average number of nucleotide differences is $25.789(\mathrm{k})$, the nucleotide diversity coefficient accounts for $17.980 \times 10^{-3} \pm 0.003(\mathrm{Pi})$. All indicators were processed with statistical significance $p<0,05$. The $\mathrm{G}+\mathrm{C}$ content above 1434 sites positions of nucleotide sequences account for 0.542 (Table 3 ).

Table 4 Neutrality Tests results based on $16 \mathrm{~S}$ rRNA region of strain bacteria Vibrio population

\begin{tabular}{ccccc}
\hline Genetic region & Tajima's D test & Fu and Li's D* test & Fu and Li's F* test* & Fu's Fs \\
\hline \multirow{3}{*}{16 S rRNA } & -0.03099 & 1.91401 & 1.49643 & 13.659 \\
\cline { 2 - 5 } & Statistical & Statistical significance: & Statistical significance: & Strobeck's $S$ \\
& significance: Not & $* *, P<0.02$ & Not significant, $0.10>P>$ & statistic: \\
& significant, $P>0.10$ & & 0.05 & 0.000 \\
\hline
\end{tabular}

Three methods namely (Tajima's D test, Fu and Li's D* and F* test, Fu's Fs) were used to test neutrality. The results in Table 4 indicated that with A negative Tajima's D signifies an excess of low frequency polymorphisms compared with initial expectation (Statistical significance: Not significant, $p>0.10$ ). Meanwhile, a positive value of $F_{S}$ (13.659) is the evidence for a deficiency of alleles, as would be expected from a recent population bottleneck (Strobeck's S statistic: 0.000). In addition, The Fu and Li's F* (statistical significance $0.10>p>0.05$ ) and value of Fu and Li's D* (Statistical significance: **, $P<0.02$ ) both yield positive ones, which showed that the evolution of the studied 30 strain bacteria Vibrio population was balancing selection, sudden contraction or in other words, rare alleles appeared in populations with low frequency, the studied population had very few individuals showing large differences in comparison with other individuals in the population (Table 4).

The phylogenetic tree shows the genetic relationship of thirty Vibrio strains which are isolated from various three different parts of the fish (S. ocellatus) using UPGMA method. In figure 3, these strains are divided into six groups. Among these, group I includes the strains of isolated Vibrio which are closely related to V. azureus. These strains mainly concentrate in the digestive system and hemorrhagic. Groups II, III and V consist of Vibrio strains, isolated in 3 different parts (brain, hemorrhagic and digestive system). They are closely related to V. alginolyticus. Group 4 includes two strains, isolated from the ulcer which are closely related to Vibrio orientalis. Group VI consists of 4 strains, concentrating in digestive system and having a close genetic relationship with V. fluvialis (Fig. 3). As observed, the appearance of isolated Vibrio on 3 organs of red drum fish showing signs of bleeding hemorrhagic are V. azureus (27,67\%), V. alginolyticus $(50 \%)$, V. orientalis $(6,67 \%)$ and V. fluvialis $(16,67 \%)$. 
Fig. 4 Phylogenetic tree of 30 strain bacteria Vibrio varieties collected based on the 16S rRNA region by the UPGMA method

\section{Discussion}

In this study, we isolated thirty strains of Vibrio from three different organs (brain, hemorrhagic site and digestive system) of $S$. ocellatus. The results showed that nucleotide sequences $16 \mathrm{~S}$ rRNA region are highly similar to those of $V$. alginolyticus, $V$. azureus, $V$. fluvialis and V. orientalis published on Genebank, ranging from 98.05 to $100 \%$. The digestive system has the most common Vibrio species (V. alginolyticus, $V$. azureus and $V$. fluvialis). None of $V$. parahaemolyticus presence, the same reported of Sohn showed that identification of Vibrio species isolated from cultured olive flounder (Paralichthys olivaceus) in Jeju Island, South Korea that none of V. parahaemolyticus 
presence too (Sohn, Kim, Jin, \& Lee, 2019). In which V. parahaemolyticus strain was a pathogen causing in shrimp disease, (Dao, Linh, \& Khanh, 2014), (Khanh et al., 2019).

The present of toxic genes related to the hemolysin of fish are found in various Vibrio sp.. Meanwhile, approximately $50 \%$ of isolates consist of toxin operon gene. All $\mathrm{V}$. parahaemolyticus isolates contained the toxR genes but the trh gene did not existence in clam (Corbicula moltkiana). Our data confirmed three isolates carried both toxR and trh genes including isolates exhibited highly similarity to $V$. fluvialis, $V$. alginolyticus, and $V$. orientalis. TDH is an enzyme that lyses human red blood cells on Wagatsuma blood agar plates, which is referred to as the Kanagawa phenomenon positive. Another toxin produced by Kanagawa phenomenon negative Vibrio strains is the tdh-related hemolysin (trh) toxin encoded by trh gene (Al-Othrubi, et al., 2011). Thermolabile hemolysin (tlh) is an another Vibrio enterotoxin that cause blood cell lysis in infected fish, th is encoded by th gene (Hasrimi, A.N., et al., 2018). Among 4 toxin genes (toxR, $t d h$, trh and $t h$ ) were investigated from Vibrio spp. causing hemorrhagic disease in $S$. ocellatus, the results showed that the frequency of the toxR gene was detected in the 15 isolates using PCR assay, lowest of $t d h$ gene was 2 isolates, trh gene was 9 isolates and the highest of $t h$ was 18 isolates using PCR assay. In addition the frequency of occurrence of toxin gene also showed that there were 5/30 Vibrio strains none carried the toxin gene (code number: YHTH12; YHTH47; YVL11; YVL26 and YVL84), 10/30 strains had only 1 toxin gene, 11/30 strains had 2 toxin genes and 4 strains carried 3 toxin genes including ( $V$. alginolyticus strain 3-31, code number YHTH44 (toxR, trh and th); V. alginolyticus strain 3- 31, code number YVL22 (toxR, trh and th); V. alginolyticus strain 3-5, code number YVL24 (toxR, tdh and th) and V. orientalis strain 5-13, code number YVL42 (toxR, trh and th). None of Vibrio carry all of 4 toxin genes. All Vibrio strains isolated from three marine fish species (S. ocellatus, Lates calcarifer and Epinephelus fuscoguttatus) was only carried one th gene present (Hoang Tan Quang et al., 2020). According Long et al, 2019 we isolated and identified the $V$. parahaemolyticus 01 strain in Thua Thien Hue province, Vietnam causing ulcer disease in S. ocellatus. The fulllength of thermolabile hemolysin (tlh) gene (1257 bp), encoding antigen thermolabile hemolysin toxin (tlh) of the Vibrio sp. was cloned and sequenced successfully. The sequence analysis of gene cloned shows a complete similarity to the V. parahaemolyticus strain (Genbank: AY289609.1) (Long et al., 2019). We further examined the presence of virulence genes homologous to those in $V$. cholerae (toxR, toxS, VPI and ace); toxR was found in $16 \mathrm{~V}$. alginolyticus strains and toxS in 17 strains out of 34. Analysed in two fishes species were sea bass (Dicentrarchus labrax) and sea bream (Sparus aurata). A positive amplification for the virulence pathogenicity island (VPI) was produced by $12 \mathrm{~V}$. alginolyticus strains. Finally, the aceexpected amplification fragment was found in $7 \mathrm{~V}$. alginolyticus isolates. Thus, the pathogenicity of $V$. alginolyticus may be the result of a combination of all these factors (Kahla-Nakbi, et al., 2009).

Six parameters were used to evaluate the diversity of 30 studied Vibrio bacteria strains. The result show that, ninety eight separate polymorphic positions (S) created 103 mutant positions (Eta) shown in 30 studied Vibrio strains classified into nine types of haplotype (h) with haplotype diversity coefficient accounting for $0.887 \pm 0.032$ $(\mathrm{Hd})$, the average number of nucleotide differences is $25.789(\mathrm{k})$, the nucleotide diversity coefficient accounts for $17.980 \times 10^{-3} \pm 0.003(\mathrm{Pi})$. All indicators were processed with statistical significance $p<0.05$. The $\mathrm{G}+\mathrm{C}$ content above 1434 sites positions of nucleotide sequences account for 0.542 .

Neutrality was tested based on three methods (Tajima, F., 1989) showing that there was an excess of low frequency polymorphisms relative to expectation, evidence for a deficiency of alleles, as would be expected from a recent population bottleneck and the evolution of the studied 30 Vibrio bacteria population was balancing selection, sudden contraction or in other words, rare alleles appeared in populations with low frequency, the studied population had very few individuals showing large differences in comparison with other individuals in the population. The phylogenetic tree shows the genetic relationship of 30 Vibrio strains using UPGMA method (bootstrap $=1000$ ) showed that these strains are divided into six groups. As observed, the appearance of isolated Vibrio on 3 organs of fish (S. ocellatus) hemorrhagic are V. azureus $(27,67 \%), V$. alginolyticus $(50 \%), V$. orientalis $(6,67 \%)$ and $V$. fluvialis $(16,67 \%)$.

\section{List of Abbreviations}


PCR: Polymerase chain reaction; TCBS: Thiosulphate Citrate Bile Salt Sucrose; tlh: Thermolabile hemolysin toxin; trh: tdhrelated hemolysin; tdh: Thermostable direct hemolysin; toxR: Toxin operon

\section{Ethics approval and consent to participate}

Not applicable

Consent for application

Not applicable

Availability of data and materials

All the data were presented in the main paper

Competing interests

The authors declare that they have no competing interests

Author's contributions

PTHY collected samples, isolated the bacterial strains, PCR method, DNA extraction and wrote the manuscript. NDQTcollected samples, analyzed the data and NQL analyzed the data, supervisor and wrote the paper. All authors read and approved the final manuscript.

\section{Funding}

The paper was supproted of a part financial by Hue University and Vietnam Ministry of Education and Training (project code number: CT-2018-DHH-07).

\section{Acknowledgement}

This study was helped by Mr. Long DT with his technician's assistance in laboratories who worked at Institute of Biotechnology, Hue University, Vietnam.

Authors' information

${ }^{1}$ University of Agriculture and Forestry, Hue University, Hue, 49000, Vietnam. ${ }^{2}$ Institute of Biotechnology, Hue University, Hue, 49000, Vietnam.

\section{References}

Al-Othrubi, S. M., Alfizah, H., Son, R., Humin, N., \& Rahaman, J. (2011). Rapid detection and E-test antimicrobial susceptibility testing of Vibrio parahaemolyticus isolated from seafood and environmental sources in Malaysia. Saudi Med. J, 32, 400-406. doi:https://pubmed.ncbi.nlm.nih.gov/21484001/

Dang, W., Zhang, M., Hu, Y.-h., \& Sun, L. (2010). Differential regulation of Sciaenops ocellatus viperin expression by intracellular and extracellular bacterial pathogens. Fish \& shellfish immunology, 29(2), 264-270. doi:https://doi.org/10.1016/j.fsi.2010.04.015

Dao, N. T. B., Linh, N. Q., \& Khanh, N. (2014). Research on some characteristics of Vibrio parahaemolyticus which causes EMS disease on juvenile shrimp at Dien Huong community, Phong Dien district, Thua Thien Hue, Vietnam. Hue University of journal of Science, 13-22.

Eldar, A., Perl, S., Frelier, P., \& Bercovier, H. (1999). Red drum Sciaenops ocellatus mortalities associated with Streptococcus iniae infection. Diseases of aquatic organisms, 36(2), 121-127. doi:http://dx.doi.org/10.3354/dao036121

$\mathrm{Fu}$, Y.-X. (1995). Statistical properties of segregating sites. Theoretical population biology, 48(2), 172197. doi:https://doi.org/10.1006/tpbi.1995.1025

Fu, Y.-X., \& Li, W.-H. (1993). Statistical tests of neutrality of mutations. Genetics, 133(3), 693-709. doi:https://www.ncbi.nlm.nih.gov/pmc/articles/PMC1205353/pdf/ge1333693.pdf

Hall, T. A. (1999). BioEdit: a user-friendly biological sequence alignment editor and analysis program for Windows 95/98/NT. Paper presented at the Nucleic acids symposium series. https://www.academia.edu/2034992/BioEdit_a_userfriendly_biological_sequence_alignment_editor_and_analysis_program_for_Windows_95_98_NT

Hasrimi, A. N., Budiharjo, A., \& Jannah, S. N. (2018). Detection of th and tdh genes in Vibrio parahaemolyticus inhabiting farmed water ecosystem used for L. Vannamei aquaculture. Journal of Physics: Conference Series, 1025, 1-9. doi:https://doi.org/10.1088/1742-6596/1025/1/012058

Hoang Tan Quang, Tran Thuy Lan, Truong Thi Hong Hai, Pham Thi Hai Yen, Tran Quang Khanh Van, Ho Thi Tung, Nguyen Quang Linh, Tram, N. D. Q. (2020). Genetic diversity and toxic genes 
analysis of Vibrio spp. isolated from white leg shrimp and marine fishes cultured in Tam Giang lagoon in Thua Thien Hue province, Vietnam. INDIAN JOURNAL OF SCIENCE AND TECHNOLOGY, 13(13), 1412-1422. doi:https://doi.org/10.17485/IJST/v13i13.161

Felsenstein J. (1985). Confidence limits on phylogenies: An approach using the bootstrap. Evolution, 39, 783-791. doi: https://doi.org/10.1111/j.1558-5646.1985.tb00420.x

Janda, J. M., Newton, A. E., \& Bopp, C. A. (2015). Vibriosis. Clinics in laboratory medicine, 35(2), 273288.

Kahla-Nakbi, A. B., Chaieb, K., \& Bakhrouf, A. (2009). Investigation of several virulence properties among Vibrio alginolyticus strains isolated from diseased cultured fish in Tunisia. Diseases of aquatic organisms, 86(1), 21-28. doi: https://doi.org/10.3354/dao02091

Khanh, N. V., Linh, N. n. Q., Lan, T. n. T. y., Vân, T. n. Q. K. n., Cơ, N. n. T. K., \& Dung, T. n. Q. c. (2019). Isolation and screening of Vibrio parahaemolyticus strains to cause acute hepatopancreatic necrosis disease in white-leg shrimps cultured in Phong Dien, Thua Thien Hue, Vietnam using 16S rRNA marker. Hue University Journal of Science: Natural Science, 128(1E), 47-58. doi: http://dx.doi.org/10.26459/hueuni-jns.v128i1E.5443

Koichiro Tamura, Masatoshi Nei, \& Kumar, S. (2004). Prospects for Inferring Very Large Phylogenies by Using the Neighbor-Joining Method. Proc Natl Acad Sci U S A, 101(30), 11030-11035. doi:https://doi.org/10.1073/pnas.0404206101

Kumar S., Stecher G., Li M., Knyaz C., \& K., T. (2018). MEGA X: Molecular Evolutionary Genetics Analysis across computing platforms. . Molecular Biology and Evolution, 35, 1547-1549. doi:https://doi.org/10.1093/molbev/msy096

Long, D. T., Hoang, N. T., Hong, H. T. K., Yen, P. T. H., Chuong, H. V., Trang, N. T. Q., \& Hiep, N. V. (2019). Isolation and DNA cloning of thermolabile hemolysin gene of Vibrio bacteria from Sciaenops ocellatus in Thua Thien Hue, Vietnam. Hue University Journal of Science: Natural Science, 128(1E), 5-14. doi:http://dx.doi.org/10.26459/hueuni-jns.v128i1E.5373

Mmanda, F. P., Zhou, S., Zhang, J., Zheng, X., An, S., \& Wang, G. (2014). Massive mortality associated with Streptococcus iniae infection in cage-cultured red drum (Sciaenops ocellatus) in Eastern China. $\begin{array}{llll}\text { African Journal of Microbiology Research, } & \text { 8(16), }\end{array}$ doi:https://doi.org/10.5897/AJMR2014.6659

Sneath, P., \& Sokal, R. (1973). Numerical Taxonomy. The principle and practice of numberical classification. WH Freeman and Co. San Francisco, 263-268. doi:https://www.jstor.org/stable/2412767?seq=1

Sohn, H., Kim, J., Jin, C., \& Lee, J. (2019). Identification of Vibrio species isolated from cultured olive flounder (Paralichthys olivaceus) in Jeju Island, South Korea. Fisheries and Aquatic Sciences, 22(1), 14. doi:https://doi.org/10.1186/s41240-019-0129-0

Tajima, F. (1989). Statistical method for testing the neutral mutation hypothesis by DNA polymorphism. Genetics, 123(3), 585-595. doi:https://www.ncbi.nlm.nih.gov/pmc/articles/PMC1203831/pdf/ge1233585.pdf

Thompson, J. D., Gibson, T. J., Plewniak, F., Jeanmougin, F., \& Higgins, D. G. (1997). The CLUSTAL_X windows interface: flexible strategies for multiple sequence alignment aided by quality analysis tools. Nucleic acids research, 25(24), 4876-4882. doi:https://doi.org/10.1093/nar/25.24.4876

Zhang, M., \& Sun, L. (2011). The tissue factor pathway inhibitor 1 of Sciaenops ocellatus possesses antimicrobial activity and is involved in the immune response against bacterial infection. Developmental \& Comparative Immunology, 35(3), 247-252. doi:https://doi.org/10.1016/j.dci.2010.10.006 